\title{
ethic@ \\ BEAUVOIR E A SITUAÇÃO DAS MULHERES: ENTRE SUBJETIVIDADE E FACTICIDADE
}

\author{
BEAUVOIR AND THE WOMEN'S SITUATION: BETWEEN \\ SUBJECTIVITY AND FACTICITY
}

\author{
THANA MARA DE SOUZA ${ }^{1}$ \\ (Universidade Federal do Espírito Santo, Brasil)
}

\begin{abstract}
RESUMO
Mostraremos, nesse artigo, que a noção de situação - compreendida como tensão entre subjetividade e facticidade - possibilita a Beauvoir sair do conceitualismo e sua essencialização do que é histórico, e ao mesmo tempo, sair do nominalismo, que recusa a noção mesma de gênero em prol de expressões abstratas e universais. Contra essas duas vertentes, a filósofa francesa aponta a necessidade de pensar a questão de gênero a partir das situações concretas de formação das crianças e jovens para encontrar, ali, as dificuldades que as mulheres encontram para se afirmarem como "nós", mas também para - ao não anular o papel dessas subjetividades no mundo - buscar ali as possibilidades de luta e modificação das próprias condições históricas.

Com base principalmente na Introdução do Primeiro Volume e na última parte do Segundo Volume do livro $O$ segundo sexo, buscaremos compreender que a afirmação de que "há mulheres", presente no texto, não resulta de um pensamento que essencializa as situações, mas o contrário, resulta de uma adoção da ética existencialista, que pressupõe como ponto de partida a descrição da concretude humana.
\end{abstract}

Palavras-chave: Beauvoir. Gênero. Situação. Subjetividade. Facticidade.

\begin{abstract}
In this article, we will show that the notion of situation - understood as a tension between subjectivity and facticity - allows Beauvoir to get out from conceptualism and its essentialization of what is historical, and at the same time to get out of nominalism, which refuses the notion of gender, adopting abstract and universal expressions. Against these two aspects, the French philosopher points out the need to think about the gender issue by concrete situations of the formation of children and young people, in order to find the difficulties that women encounter in affirming themselves as "we", but, as well, to seek there the possibilities of struggle and modification of the historical conditions, without to negate the role of these subjectivities in the world.

Based mainly on the Introduction of the First Volume and the last part of the Second Volume of the book The second sex, we will try to understand that the affirmation that "there are women", present in the text, does not result from a thought that essentialises the situations, but on the contrary, results from an adoption of existentialist ethics, which presupposes as a starting point the description of human concreteness.
\end{abstract}

Keywords: Beauvoir. Gender. Situation. Subjectivity. Facticity. 


\section{Introdução}

Beauvoir propõe, em seu livro $O$ segundo sexo, pensar a questão de gênero para além das questões biológicas, embora essas também nos constituam. Sem reduzir o gênero ao sexo - mesmo que sem utilizar as distinções realizadas no século XXI - , a filósofa francesa ensaia colocar a questão do gênero em perspectivas históricas e existencialistas, ou seja, a partir de uma base teórica que pensa as subjetividades ${ }^{2}$ sempre inseridas em um certo contexto, o qual não pode ser desconsiderado, e, ao mesmo tempo, não é capaz de anular as ações humanas.

É por meio de um jogo entre imanência e transcendência, de uma tensão entre subjetividade e historicidade, que podemos compreender a condição das mulheres, sem cair em um essencialismo, que naturaliza o que é histórico, e, ao mesmo tempo, sem cair em um nominalismo, que também ignora a história ao afirmar que não há mulheres. Em outras palavras, Beauvoir adota um viés materialista ao propor um pensamento que leva em conta os dois aspectos conjuntamente, sem reduzir um ao outro, nos fazendo lembrar a famosa frase marxista de que os humanos fazem a história, em situações historicamente determinadas.

No entanto, se a crítica ao pensamento essencialista é bastante conhecida, a compreensão da afirmação de que "existem mulheres" é ainda muito discutida, principalmente por algumas feministas, que veem nessa afirmação um essencialismo ou binarismo pressuposto, incoerente com um pensamento que critica qualquer forma de naturalização.

É sobre essa questão que queremos nos centrar nesse artigo: na compreensão de como Beauvoir critica o abstracionismo do nominalismo, não por conta de alguma estrutura prévia, mas por conta justamente da facticidade. "Recusar as noções de eterno feminino, alma negra, caráter judeu, não é negar que haja hoje judeus, negros e mulheres; a negação não representa para os interessados uma libertação, e sim uma fuga inautêntica" (BEAUVOIR, 2016, p. 10, vol. I).

Sem entrar na discussão feita pelas leituras críticas posteriores, nossa intenção é propor uma compreensão da fillosofia de Beauvoir a partir das noções por ela trabalhadas, principalmente as de situação, subjetividade e facticidade. Concordamos com Juliana Missagia (2015, p. 164) de que há um “caráter promissor do diálogo entre feminismo e fenomenologia”, e é por meio de uma compreensão teórica que tentaremos mostrar que sua 
filosofia, ao afirmar que existem mulheres, longe de ceder ao essencialismo, enfatiza ainda mais a importância das condições históricas em nossa constituição.

Seguindo o texto de Missagia sobre os diálogos entre fenomenologia e feminismo, e as contribuições pouco desenvolvidas da primeira ao segundo, mostraremos como o texto de Beauvoir permite "superar a ideia essencialista sobre o que é ser mulher (...) e, ao mesmo tempo, não diluir completamente a possibilidade do feminismo enquanto movimento político" (MISSAGIA, 2015, p. 173). Embora essa descrição seja sobre a fenomenologia de modo geral, tentaremos mostrar aqui que ela se aplica a $O$ segundo sexo, dado que, por meio das noções de jogo e situação, a filósofa francesa permitiria afirmarmos que há um "nós" sem cair em universalizações, que tendem a anular as diferenças.

Assim, faremos uma análise teórica de algumas noções trabalhadas para demonstrar que é por meio da adesão ao materialismo, sem no entanto, reduzir-se a ele, que Beauvoir consegue ir além do conceitualismo e do nominalismo, evitando as naturalizações e possibilitando a luta comum.

\section{Desenvolvimento}

Para isso, é necessário que compreendamos de modo mais aprofundado os pressupostos teóricos filosóficos adotados e explicitados na Introdução ao Primeiro Volume de $O$ segundo sexo. Só por meio de uma análise conceitual é que conseguiremos estabelecer em que perspectiva o existencialismo se coloca - o que já fica claro logo no Primeiro Parágrafo, quando contrapõe seu pensamento a duas teorias: conceitualismo e nominalismo, sem adotar nenhuma delas.

Por um lado - o mais enfatizado quando se discute sua filosofia - Beauvoir (2016, p. 13 , vol. I) expõe o que chama de "a teoria do eterno feminino" como aquela que, por meio de definições absolutas, faz de cada mulher a encarnação do Modelo pré-definido. Tal como o sensível participa do Inteligível na filosofia platônica, as mulheres reais são mulheres porque participariam da Ideia de Mulher, já definida anteriormente. Pensam assim os conceitualistas, que explicam e definem a existência por meio de essências e, com isso, naturalizam o que é histórico. Contra eles, Beauvoir não deixa de insistir, ao longo dos dois volumes, que não se pode compreender a historicidade por meio da natureza, porque aquela é justamente a transcendência desta. 
O conceitualismo perdeu terreno: as ciências biológicas e sociais não acreditam mais na existência de entidades imutavelmente fixadas, que definiriam determinadas características como as da mulher, do judeu ou do negro; consideram o caráter como uma reação secundária a uma situação (BEAUVOIR, 2016, p. 10, vol. I).

É, pois, por meio da noção de situação, grifada pela autora, que se pretende criticar os pensamentos essencialistas e a tentativa de delimitar as mulheres reais a uma pré-concebida Ideia de Mulher: se se parte do existencialismo, é à existência, às condições históricas, que precisamos nos voltar - e é esse o movimento realizado por Beauvoir no primeiro volume do livro, quando combate as teorias que tentam anular o que é histórico e substitui-lo por destinos, sejam biológicos, psicanalíticos ou materialistas. "O que se constata é que os textos de Beauvoir primam pela pontuação temporalizada e despertam o leitor tanto para a situação histórica por ela descrita quanto para a reflexão acerca do valor da historicidade textual" (DOS SANTOS, 2012, p. 922).

Assim, Beauvoir coloca-se na contramão do conceitualismo e afirma que é preciso teorizar a problemática das mulheres, negros e judeus ${ }^{3}$ a partir da concretude, ou seja, a partir da construção histórica. E é nesse sentido que se deve entender o famoso trecho do início do segundo volume, quando se anuncia que "ninguém nasce mulher: torna-se mulher. Nenhum destino biológico, psíquico, econômico define a forma que a fêmea humana assume no seio da sociedade" (BEAUVOIR, 2016, p. 11, vol. II). Não nascemos mulher porque não há uma essência ou natureza que nos determine de antemão - o que, por sua vez, significa afirmar que há uma existência que nos torna mulheres. E é exatamente esse segundo trecho da frase "ninguém nasce mulher: torna-se mulher" (grifo nosso) que permitirá a Beauvoir afirmar que, se não há destino, há situação - que não determina, mas não deve ser ignorada -; por meio da qual podemos ir além do conceitualismo e, ao mesmo tempo, além do nominalismo, como veremos agora.

Voltando à Introdução do Primeiro Volume, podemos perceber que, logo depois de criticar o conceitualismo por não considerar a situação concreta, Beauvoir descreve uma outra teoria com a qual não concorda: o nominalismo. Afirmar que não há uma essência feminina não é o mesmo, para a filósofa, que afirmar que a palavra fêmea não tem nenhum conteúdo, ou que não existem mulheres. Contra as teorias que tentam ignorar o problema de gênero e se contentam com a afirmação de uma igualdade abstrata e formal - "todos somos seres 
humanos" -, Beauvoir aponta para a necessidade de partir de distinções que moral e politicamente são realizadas. Em outras palavras, "sem dúvida, a mulher é, como o homem, um ser humano. Mas tal afirmação é abstrata; o fato é que todo ser humano concreto sempre se situa de um modo singular" (BEAUVOIR, 2016, p. 10, vol. I). E sendo singularmente situado, é colocado e se coloca de forma diferenciada. Ou seja: é preciso admitir que, embora todos sejamos seres humanos, a sociedade, em tais circunstâncias, distingue-nos em categorias, atribuindo valores, direitos e deveres distintos a cada um; não como justificativa para o que somos, mas como uma descrição do modo como somos vistos e categorizados. ${ }^{4}$ É$^{2}$ por isso que o existencialismo insistirá na necessidade de não esvaziar totalmente o sentido da palavra mulher: não porque está inscrito em um mundo das essências, mas porque concretamente podemos perceber um modo geral de como as pessoas são categorizadas; a fim de possibilitar uma luta que saia do individual e chegue ao coletivo: é "necessário manter essa categoria, justamente a partir do reconhecimento de experiências comuns de opressão e pela possibilidade de reivindicar direitos" (MISSAGIA, 2015, p. 178).

Há o reconhecimento, portanto, de que a sociedade se estabelece a partir de características concebidas e simbolizadas de modos semelhantes em certo período ou cultura - e o nominalismo, ao ignorar essas distinções, mostra-se tão abstrato quanto o conceitualismo.

Assim, quando se coloca contra o nominalismo e a tendência de dissolver o problema do gênero em afirmações genéricas e abstratas, Beauvoir parte da mesma noção que guiou sua crítica ao conceitualismo: a situação. Longe de colocar o "tornar-se mulher" como um imperativo, temos, aqui, a constatação ou descrição fenomenológica de que a sociedade europeia, na primeira metade do século XX, classifica as pessoas em homens e mulheres.

E, em verdade, basta passear de olhos abertos para comprovar que a humanidade se reparte em duas categorias de indivíduos, cujas roupas, rostos, corpos, sorrisos, atitudes, interesses, ocupações são manifestamente diferentes; talvez essas diferenças sejam superficiais, talvez se destinem a desaparecer. $\mathrm{O}$ certo é que por enquanto elas existem com uma evidência total (BEAUVOIR, 2016, p. 11, vol. I).

Ao observar os diferentes modos como a sociedade divide a humanidade nessas duas categorias, Beauvoir enfatiza que se trata de uma descrição de sua época, a qual pode se revelar superficial e até mesmo desaparecer - quando, então, talvez seja possível pensar em 
outras diferenciações. Isso significa que não temos, em $O$ segundo sexo, uma designação absoluta, mas que parte de uma descrição fenomenológica - e é porque adota a metodologia fenomenológica que podemos afirmar que existem homens e mulheres, ao menos na primeira metade do século XX na Europa, com simbolizações comuns que permitem agrupar um grupo como sendo mulheres, mesmo que não idênticas. Sem anular os diferentes modos de lidar com a facticidade, é dela que se parte, como aponta Missagia (2015, p. 179): “experiências femininas, embora possam variar enormemente de uma mulher para outra, possuem traços em comum passíveis de descrição". Não por acaso, o objetivo do segundo volume do ensaio filosófico é o de descrever a experiência vivida (título do volume), o modo como a sociedade europeia forma as meninas e os meninos, ao menos desde o segundo desmame ${ }^{5}$, de maneira não apenas diferenciada, mas também hierarquizada. É na infância, tal como vivenciada na década da escrita do livro, que as simbologias e opressões começam a aparecer, e é na adolescência que elas se tornam mais explícitas. Percorrendo a formação da infância à iniciação sexual, Beauvoir explora a noção de facticidade e sua fundamental importância para compreender como às mulheres, subjetividades transcendentes, não foram dadas as mesmas condições de se colocarem como transcendência, já que é por meio da educação e formação dadas pela família e pela sociedade que se tenta naturalizar o feminino como inferioridade e passividade.

É com a noção de situação, pensada como jogo entre subjetividades e facticidade (condição histórica), que Beauvoir propõe, desde o início até o final do livro, a ultrapassagem do conceitualismo e ao mesmo tempo do nominalismo; ou seja, um pensar a questão de gênero de forma a não admitir, em nenhum momento, essencialismos - o que, por sua vez, implica no reconhecimento de traços comuns, mesmo que provisórios: "Se a função de fêmea não basta para definir a mulher, se nos recusamos também a explicá-la pelo 'eterno feminino' e se, no entanto, admitimos, ainda que provisoriamente, que há mulheres na Terra, teremos que formular a pergunta: o que é uma mulher?” (BEAUVOIR, 2016, p. 11, vol. I), pergunta essa que será respondida justamente pelo que há de provisório: essas roupagens destinadas de formas distintas a cada um dos gêneros. "Perguntar 'O que é uma mulher?', como o faz Simone de Beauvoir na Introdução (I, 13), é, portanto, um interrogar-se sobre sua condição passada e atual, e não sobre sua 'natureza'” (LECARME-TABONE, 2008, pp. 63-64).

Mesmo que não utilize a linguagem que se tornou mais corrente no século XXI sobre sexo, gênero e orientação sexual, podemos ver em $O$ segundo sexo a preocupação com a não identificação entre o ser fêmea (biológico) com o ser mulher (gênero), e o ser mulher não 
como natureza, mas como uma construção que ocorre em uma historicidade já marcada por signos e valores. O jogo entre as subjetividades e as condições históricas será mantido como tensão por Beauvoir, sem que nenhum dos elementos se subtraia ao outro e sem pensar um de forma separada do outro: se, por um lado, as subjetividades só existem localizadas geográfica e temporalmente, por outro, o contexto não existe sem o modo como as pessoas, ao vivê-lo, podem ressignificá-lo. Subjetividades e historicidade convivem nesse tenso jogo de atração e repulsão, e é por conta desta mesma condição histórica que se pode afirmar que há mulheres, como mais de uma vez Beauvoir adverte:

Quando emprego as palavras 'mulher' ou 'feminino' não me refiro evidentemente a nenhum arquétipo, a nenhuma essência imutável; após a maior parte de minhas afirmações cabe subentender: 'no estado atual da educação e dos costumes'. Não se trata aqui de enunciar verdades eternas, mas de descrever o fundo comum sobre o qual se desenvolve toda a existência feminina singular (BEAUVOIR, 2016, p. 7, vol. II).

E, no estado atual de educação e costumes, é possível identificar traços comuns que tornam um grupo de seres humanos, mulheres, as quais, por serem liberdade ${ }^{6}$, podem lutar por sua libertação.

Com a noção de situação, torna-se possível afirmar que existem mulheres e que estas têm possibilidade de lutar pela autonomia, de forma a criar outra situação, na qual não faça mais sentido falar em distinção de gênero. Admitir que na 'condição atual' é possível afirmar que há mulheres não é destiná-las a permanecer como tais, pelo contrário, é voltar-se de forma crítica paras as condições materiais e morais a fim de poder transformá-las.

\section{A subjetividade}

Assim, a facticidade nos permite afirmar que "há mulheres", enquanto a noção de subjetividade nos permite afirmar que essa facticidade pode ser modificada - e é na conjunção de ambas que devemos, para Beauvoir, pensar a condição das mulheres nesse mundo. É por isso que toda a primeira parte do Primeiro Volume se equilibra de forma instável entre a importância do corpo, da sexualidade e dos aspectos econômicos, e o modo como, ao significá-los, o ser humano os transcende, não sendo, portanto, limitados de forma absoluta por eles. Não se trata de ignorar as diferenças fisiológicas entre o sexo masculino e o 
feminino, entre macho e fêmea, pelo contrário: ela admite que o biológico tem uma importância grande na constituição das pessoas, e diz que é impossível pensar o humano sem sua corporeidade; mas, ao enfatizar seu papel, não o coloca como determinante para as questões morais e a definição do que é ser mulher:

Esses dados biológicos são de extrema importância: desempenham na história da mulher um papel de primeiro plano, são um elemento essencial de sua situação. Em todas as nossas descrições ulteriores, teremos que nos referir a eles. Pois, sendo o corpo o instrumento de nosso domínio do mundo, este se apresenta de modo inteiramente diferente segundo seja apreendido de uma maneira ou de outra. Eis por que os estudamos tão demoradamente; são chaves que permitem compreender a mulher. Mas o que recusamos é a ideia de que constituem um destino imutável para ela. Não bastam para definir uma hierarquia dos sexos; não explicam por que a mulher é o Outro; não a condenam a conservar para sempre essa condição subordinada (BEAUVOIR, 2016, p. 60, vol. I).

Em outras palavras, o sexo não define o gênero e o ser mulher (segundo a condição atual de ensino e costumes) não pode ser reduzido ao ser fêmea. É o que reaparece no segundo volume para explicar como, para além da constatação da diferença físiológica, importante é o modo como ela é vivida e significada pela sociedade. A menstruação, por exemplo, acontecimento apenas do sexo feminino, era colocada, na primeira metade do século XX, como uma maldição e sua primeira vez era vivenciada pela adolescente como um trauma. Mas isso ocorria, segundo Beauvoir, não porque em si mesma a menstruação traga limites e impossibilidades, mas porque, tratada como tabu, leva a adolescente a se sentir mal e menor. Sem ignorar a importância do fisiológico, a filósofa enfatiza a significação no lugar da determinação: não é o trauma da menstruação que causa timidez e vergonha à adolescente, mas é porque a ensinam a se envergonhar de seu corpo nesse momento que a menstruação é vivida como trauma. Para além da constatação dos dados, há a significação deles, a valoração do que ocorre. É, pois, a subjetividade, compreendida como transcendência que leva o dado consigo mas a ele não se limita, que tem o papel de criar, nesse mundo com sentidos já constituídos, novos valores e possibilidades. Em uma sociedade que admite a menstruação como um acontecimento normal da sexualidade feminina, sem que esta precise esconder e se envergonhar dela, teríamos uma vivência bem menos traumática - e nenhuma adolescente se sentiria menos capaz pelo fato de menstruar.

Em $O$ segundo sexo, a descontinuidade entre sociedade humana e natureza (a humanidade não é uma simples espécie natural e o humano se realiza pelo ato de ultrapassar a natureza) é parte substantiva dos argumentos de Beauvoir. Mesmo referindo-se à distinção de sexos como um dado 
biológico, ela afirma a não correspondência entre fêmeas e mulheres (KOFES, 2008, p. 871).

Se os dados (a facticidade) são essenciais para a compreensão da situação, não podemos esquecer o papel ativo das subjetividades na valoração deles. Toda a Primeira Parte do Volume I dialoga com a biologia, a psicanálise e o materialismo histórico para mostrar que o fisiológico, o sexual e o econômico importam, mas não são, isolados, determinantes para delimitar o gênero. Somos todos esses aspectos como um modo geral de sermos-no-mundo, mas nenhum deles, separadamente, deveria ser visto como o que impossibilita nossa transcendência, nossa projeção no mundo $^{7}$. E do mesmo modo que o físiológico, a sexualidade e a economia são valoradas de um modo ou outro, dependendo da projeção humana.

Se adota uma perspectiva materialista ${ }^{8}$, ou, em melhores palavras, se admite que o biológico e o sexual são valorados de formas distintas segundo o "contexto econômico e social” (BEAUVOIR, 2016, p. 83, vol. I), Beauvoir não concorda com o que chama de "monismo econômico de Engels" (BEAUVOIR, 2016, p. 90, vol. I) porque este reduz todas as ações humanas a um só aspecto - crítica que poderá ser reencontrada, segundo Djamila Ribeiro, em seu prefácio a "Mulheres, Raça e Classe", em Angela Davis, dado que "mesmo sendo marxista, Davis é uma grande crítica da esquerda ortodoxa que defende a primazia da questão de classe sobre as outras opressões" (RIBEIRO, 2016, p. 12). De modo semelhante, Beauvoir se recusa a pensar a condição das mulheres apenas pela questão econômica:

Para descobrir a mulher não recusaremos certas contribuições da biologia, da psicanálise, do materialismo histórico, mas consideraremos que o corpo, a vida sexual, as técnicas só existem concretamente para o homem na medida em que os apreende dentro da perspectiva global de sua existência. $\mathrm{O}$ valor da força muscular, do falo, da ferramenta só se poderia definir num mundo de valores: é comandado pelo projeto fundamental do existente transcendendo-se para o ser (BEAUVOIR, 2016, p. 91, vol. I).

É, pois, a perspectiva global da existência que interessa a Beauvoir descrever e criticar, sem se limitar a apenas um de seus aspectos e reduzir todos os outros a este único aspecto; e sem determinar absolutamente as subjetividades por esses fatos, na medida em que estas transcendem o dado em direção ao que ainda não existe. Pensar a perspectiva global é propor uma intersecção dos diversos fatores históricos e não reduzir o papel que as subjetividades têm na construção, significação e transformação deles. 
Mas não podemos pender demais o lado da balança e convém, agora, de acordo com a proposta de Beauvoir, tensioná-la, para obter um maior equilíbrio na situação. Assim, se enfatizamos até agora a transcendência das subjetividades como forma de não determinação total $^{9}$, seja ela biológica, sexual ou econômica, é preciso agora compreender os motivos pelos quais, sendo tão ser humano (e, portanto, transcendência) quanto os homens, as mulheres encontram dificuldades em se afirmar como um "nós" e lutar pela modificação de valorações adotadas em relação ao gênero. Para responder a essa questão, Beauvoir aponta justamente o peso da facticidade para a constituição das subjetividades e como a questão de gênero não está dissociada de outras duas: raça e classe. Mesmo que não desenvolva essa problemática, temos a indicação de que a intersecção dessas questões torna mais difícil a união das mulheres em busca de sua libertação - que é a possibilidade efetiva de transcenderem os dados.

\section{A facticidade}

Beauvoir adota a concepção de Lévi-Strauss, baseada em estudos de campo, de que a passagem do estado de Natureza ao de Cultura se define pela aptidão humana de pensar em sistemas de oposição. A realidade social se dá justamente na colocação da dualidade, e, no caso da intersubjetividade, como alteridade, tal como Hegel descreve em sua teoria. Tem-se, então, como pressuposto, que a sociedade se coloca em termos de conflito, da afirmação de um "Eu" que só existe por meio da afirmação simultânea do "Outro". "O sujeito só se põe em se opondo: ele pretende afirmar-se como essencial e fazer do outro o inessencial, o objeto" (BEAUVOIR, 2016, p. 14, vol. I). Qualquer grupo, comunidade, país, se coloca como um "nós" diante de "outros": o estrangeiro, por exemplo, é um outro para "nós", que nascemos nesse país. Mas o importante, para que essas relações intersubjetivas se equilibrem, é que o outro, por sua vez, também realize o mesmo movimento: os estrangeiros se colocam como um "nós" diante dos nativos, "outros". Há uma reciprocidade que permite a relativização da afirmação, e, com isso, uma não dominação total de um grupo pelo outro. Mesmo quando ocorre uma dominação por causa numérica (um grupo ser em menor quantidade que outro) ou por conta de algum acontecimento específico, ela tende a ser temporária e possibilita que o grupo oprimido se reúna e se coloque também como um "nós" - algo que, no entanto, segundo Beauvoir, ainda não teria acontecido com as mulheres.

Nesse caso, os homens se afirmam como "nós", colocando as mulheres como "Outro", mas o movimento contrário não se realiza porque estas tinham, na primeira metade do século 
$\mathrm{XX}$, muita dificuldade de constituir um grupo que colocasse os homens, por sua vez, como "Outro" - a fim de equilibrar essa relação intersubjetiva. E à pergunta "por que as mulheres não contestam a soberania do macho? (BEAUVOIR, 2016, p. 14, vol. I), a filósofa responde por meio de uma comparação com os negros dos EUA, os judeus e os proletariados.

Não se trata, no caso da relação entre homens e mulheres, de uma desigualdade numérica, que permitiria mais facilmente que a maioria imponha por um tempo sua violência à minoria - como é com os judeus. Do mesmo modo, não podemos encontrar a origem dessa desigualdade em um acontecimento histórico, que faria dois povos separados se conhecerem e um dominar o outro - tal como a colonização e escravidão dos negros africanos nos EUA. As mulheres nunca constituíram um grupo separado dos homens, unidas a eles devido a um acontecimento: se assim fosse, haveria um "antes", um passado e uma tradição comum que facilitaria a união das mulheres. Também não podemos dizer que a situação das mulheres é parecida com a dos proletariados, dado que estes surgem a partir de um desenvolvimento histórico. Temos, assim, uma relação das mulheres com os homens que se mostra ímpar, até mesmo porque, se é possível a todos os outros oprimidos imaginarem a eliminação dos opressores, o mesmo não ocorre aqui: se houver eliminação dos homens, haverá junto a eliminação da espécie humana.

Sem um passado ou história própria, sem uma "solidariedade de trabalho e interesses" (BEAUVOIR, 2016, p. 16, vol. I) e sem até mesmo uma "promiscuidade espacial" (BEAUVOIR, 2016, p. 16, vol. I) que permita que o grupo se constitua como comunidade, as mulheres se dispersam entre os homens e se separam, tendo dificuldade em afirmar-se como um "nós", que relativizaria a dominação dos homens, "Outros". E isso ocorre não porque as mulheres são incapazes de lutar ou são intelectualmente inferiores, mas porque "[elas] não têm os meios concretos de se reunir em uma unidade que se afirmaria em se opondo" (BEAUVOIR, 2016, p. 16, vol. I). É a concretude, a facticidade, que torna mais difícil a libertação feminina - principalmente porque o ser mulher não está dissociado do ser burguesa/proletária e/ou negra/branca. Em outras palavras, sem um passado separado dos homens, as mulheres se dispersam e se encontram mais juntas a homens da mesma classe e raça que de outras mulheres - algo que será discutido brilhantemente por Angela Davis em Mulheres, Raça e Classe, mas que já aparece, mesmo que de modo apenas indicativo, em 1949: 
Vivem dispersas entre os homens, ligadas pelo habitat, pelo trabalho, pelos interesses econômicos, pela condição social a certos homens - pai ou marido - mais estreitamente do que a outras mulheres. Burguesas são solidárias dos burgueses e não das mulheres proletárias; brancas, dos homens brancos e não das mulheres negras (BEAUVOIR, 2016, p. 16, vol. I).

A questão de gênero não pode, portanto, ser separada da questão de raça e de classe e é por haver essa intersecção que as mulheres encontram dificuldades na união, já que, se for burguesa, é mais provável que se una ao marido burguês dono da fábrica que às mulheres operárias dessa fábrica, oprimidas em seu trabalho; e se for branca, é mais provável que se una ao marido branco que escraviza e que não fique ao lado das mulheres negras na luta contra a escravidão.

Há uma interligação entre os problemas de raça, classe e gênero, e este acabou por ser, na primeira metade do século XX na Europa, subordinado aos outros, tornando, assim, mais difícil a elaboração de uma pauta feminina comum. Até mesmo os movimentos sufragistas femininos do final do século XIX nos EUA, como aponta Davis ${ }^{10}$, em sua maior parte, se constituíram como um movimento de mulheres brancas burguesas que, em diversos momentos, não admitiram os mesmos direitos às operárias e negras.

Nos capítulos 4 e 7, Davis mostra como o movimento sufragista foi construído em meio a diversas incompreensões e preconceitos por parte das mulheres brancas e burguesas que lideravam a reivindicação. Enquanto o sufrágio negro era baseado na ideia de que o voto era uma medida de sobrevivência, "as líderes do movimento pelos direitos das mulheres do período pós-guerra tendiam a ver o voto como um fim em si mesmo" (DAVIS, 2016, p. 88), de modo que dificilmente aceitavam as reivindicações do movimento negro. Essa incompreensão inicial acabou por ser acentuada na última década do século XIX, quando "a campanha pelo sufrágio feminino começou a aceitar definitivamente o abraço fatal da supremacia branca" (DAVIS, 2016, p. 121), de forma a até mesmo se recusar, na convenção de Nawsa, a defender uma irmã negra.

Assim, o movimento sufragista nos EUA, liderado por mulheres brancas e burguesas, colocou-se na maior parte das vezes ao lado de homens brancos burgueses e contra outras mulheres, negras e proletárias. A dificuldade apontada, mas não trabalhada, por Beauvoir, de união das mulheres com condições econômicas e raciais distintas, é o tema mesmo do livro de Ângela Davis. Embora Beauvoir identifique o mito do eterno feminino ao modo como a mulher europeia, branca e burguesa é vista - sem tematizar essa questão, assumindo que é um 
mito universal, válido para todas as mulheres, o que é acertadamente criticado por Davis (e portanto, não se trata aqui de identificar seus pensamentos), ambas caminham na mesma direção ao relatar essa intersecção do gênero com a raça e a classe social como facticidades que colocaram mulheres contra mulheres e dificultaram a formação de uma luta de gênero.

Davis também mostra o quanto a questão de classe trazia problemas ao movimento sufragista, na medida em que as mesmas mulheres que faziam petição para fornecer cadeiras para balconistas tinham, em suas casas, empregadas domésticas em condições de trabalho tão ruins quanto as balconistas. "As mulheres brancas - incluindo as feministas - demonstraram uma relutância histórica em reconhecer as lutas das trabalhadoras domésticas” (DAVIS, 2016, p. 104).

Desse modo, podemos afirmar que Davis confirma, ao descrever a história do movimento sufragista nos EUA, a citação de Beauvoir sobre a dispersão das mulheres na intersecção entre raça e classe, de modo que há dificuldades delas se juntarem em um "nós" e articularem uma luta conjunta. É a facticidade, ao não separar o gênero da raça e da classe, que possibilita menos condições concretas para a unificação da luta das mulheres e sua afirmação efetiva de transcendência. E é por reduzir todos os problemas a apenas um aspecto - o de classe - que o marxismo também precisa ser criticado, como enfatiza Beauvoir em entrevista à televisão na década de $70^{11}$ : ali, tudo se passa como se a questão de gênero estivesse subordinada à questão de classe e fosse resolvida por meio dela. Ao contrário, a filósofa aponta, em um olhar retrospectivo à obra de 49, que os problemas de gênero continuam mesmo nas sociedades ditas socialistas. Se a libertação das mulheres passa necessariamente por uma outra vivência da família e do trabalho, não se pode restringir o processo de libertação a isso. É necessária uma libertação moral e política que redefina a educação e formação das crianças, de modo a criar um passado comum aos meninos e meninas, e, com isso, facilitar uma igualdade concreta no mundo adulto. ${ }^{12}$

Assim, se a noção de subjetividade como transcendência nos permitiu sair de um pensamento determinista que não deixaria espaço para a possibilidade de modificação, a noção de facticidade nos permite compreender como, apesar de também ser um ser humano, as mulheres encontram cerceamentos que tentam impossibilitar o exercício de autonomia, de afirmação de sua subjetividade. Sem determinismo histórico e sem abstracionismo solipsista, Beauvoir propõe pensar a condição da mulher como uma situação historicamente construída e passível de modificação, mesmo que complexa e difícil, justamente por conta da intersecção 
das questões de gênero, raça e classe e por conta da estruturação social que tenta limitar as mulheres em suas atividades econômicas, morais e políticas.

\section{O equilíbrio instável}

Longe de jogar na mulher isolada a responsabilidade total por sua condição de oprimida, Beauvoir insiste no peso da situação histórica em que ela se encontra, para compreendê-la. A subjetividade livre nunca está dissociada da concretude na qual ela aparece, e é a partir dessa facticidade que devemos nos construir. Assim, se há menos mulheres no mundo das chefias, dos negócios, das universidades, não é porque livremente não o desejamos, mas porque também as situações que temos que enfrentar são muito distintas e mais difíceis que alguém do gênero masculino normalmente enfrenta. É importante, pois, buscar a situação concreta, esse jogo entre subjetividade e facticidade, para compreender como as mulheres constroem a história em uma situação historicamente determinada. E qual era a situação geral das mulheres francesas no ano de 1949 ?

Estamos, já, com o reconhecimento formal dos direitos iguais em boa parte da Europa, mas não ainda com a não criminalização do aborto e direitos concretos iguais. A ênfase de Beauvoir é num passo muito importante que foi dado, por um lado, pela luta das mulheres, e por outro, pela necessidade que os homens tiveram de chamá-las ao mundo do trabalho (por conta das guerras). Segundo ela, "foi pelo trabalho que a mulher cobriu em grande parte a distância que a separava do homem" (BEAUVOIR, 2016, p. 503, vol. II). Afinal, ao ir ao trabalho, a mulher também passa a ocupar as ruas e com o salário, mesmo que ainda muito menor que o que o homem recebe pelo mesmo serviço, consegue relativamente uma maior autonomia.

No entanto, se se constitui como caminho importante em direção à libertação da mulher, à sua luta por reconhecimento e respeito à sua subjetividade, o trabalho também pode se apresentar como um símbolo das maiores dificuldades pelas quais as mulheres passam no diaa-dia. É o que Beauvoir diz: "Não se deve entretanto acreditar que a simples justaposição do direito de voto a um ofício constitua uma perfeita libertação" (BEAUVOIR, 2016, p. 503, vol. II), dado que "a estrutura social não foi profundamente modificada pela evolução da condição feminina" (BEAUVOIR, 2016, p. 504, vol. II).

Mesmo que econômica e formalmente haja mais igualdade entre homens e mulheres, não houve, ao mesmo tempo, uma transformação cultural, moral e política que caminhasse no 
mesmo sentido. E por isso o próprio ato de trabalhar se torna mais complexo e pesado para as mulheres.

Beauvoir descreve o quanto as mulheres, mesmo que adquirindo teoricamente maior autonomia por conta do trabalho, não receberam ajuda da sociedade para se tornarem concretamente iguais aos homens. O que vemos é a conquista de direitos formais (constituição, igualdade de direitos, direito ao voto etc.) e de direitos trabalhistas que não se traduziram em direitos morais e políticos iguais. Desse modo, o trabalho realizado pelas mulheres aparece de forma ambígua, ora como aquele que possibilita a busca da libertação, ora como aquele que traz mais armadilhas à libertação, na medida em que faz aumentar as exigências em relação ao Mito Mulher.

É o que ocorre quando as mulheres trabalham o dia todo fora de casa e na volta à casa continuam responsáveis sozinhas pelos trabalhos domésticos e cuidados com os filhos. É o que ocorre quando, solteira, uma mulher assume um cargo em outra cidade e para lá vai sozinha, precisando zelar o tempo todo por sua "reputação", já que toda a pequena cidade olha essa forasteira e a julga, enquanto dá mais liberdade para o homem solteiro na mesma situação. Nesses casos, o trabalho traz consigo uma série de exigências a mais, que tentam impedir que a mulher, mesmo com um salário, consiga sua libertação. Ou seja: há uma cobrança moral e social que persiste mesmo quando a mulher consegue a libertação econômica.

Mesmo com igualdade econômica, que é realidade para poucas mulheres mesmo no século XXI, não há uma igualdade moral e política.

Existe hoje um número bem grande de privilegiadas que encontram em sua profissão uma autonomia econômica e social. São elas que pomos em questão quando indagamos das possibilidades da mulher e de seu futuro. Eis por que, embora constituam ainda apenas uma minoria, é particularmente interessante estudar de perto sua situação (...). Em verdade, nada autoriza a dizer que seguem um caminho errado, e no entanto é certo que não se acham tranquilamente instaladas em sua nova condição: não passaram, ainda da metade do caminho. A mulher que se liberta economicamente do homem nem por isso alcança uma situação moral, social, psicológica idêntica à dele. A maneira por que se empenha em sua profissão e a ela se dedica depende do contexto constituído pela forma global de sua vida. Ora, quando inicia sua vida de adulto, ela não tem atrás de si o mesmo passado de um rapaz; não é considerada de maneira idêntica pela sociedade; o universo apresentase a ela numa perspectiva diferente. $O$ fato de ser uma mulher coloca hoje problemas singulares perante um ser humano autônomo (BEAUVOIR, 2016, pp. 505-506, vol. II). 
O não acompanhamento da igualdade moral e política junto com a igualdade econômica traz problemas singulares às mulheres que buscam se libertar por meio do trabalho. Essa mulher privilegiada que encontra igualdade econômica em seu trabalho precisa fazer uma série de concessões, sacrifícios e acrobacias para tentar alcançar um equilíbrio. A ela muitos mais desafios se colocam por ter se aproximado economicamente do homem, e é por isso que Beauvoir diz que o trabalho é um passo necessário, mas não suficiente. "As circunstâncias objetivas tampouco lhe são favoráveis. É sempre difícil ser um recém-chegado que tenta abrir caminho através de uma sociedade hostil ou, pelo menos, desconfiada" (BEAUVOIR, 2016, p. 522, vol. II). Não é por conta de sua "natureza de mulher", que ela normalmente ousa menos. É por conta das situações historicamente impostas a ela que lhe é dado menos chance de ousar, ou um custo muito maior quando ousa.

\begin{abstract}
A mulher não se define nem por seus hormônios nem por misteriosos instintos e sim pela maneira por que reassume, através de consciências alheias, o corpo e sua relação com o mundo; o abismo que separa a adolescente do adolescente foi cavado de maneira acertada desde os primeiros anos da infância; não há como impedir mais tarde que a mulher não seja o que foi feita e ela arrastará sempre esse passado atrás de si; pesando-se com esse passado, compreende-se com clareza que seu destino não se acha fixado na eternidade. Por certo, não se deve crer que baste modificar-lhe a situação econômica para que a mulher se transforme: esse fator foi e permanece primordial de sua evolução; mas enquanto não tiver acarretado as consequências morais, sociais, culturais etc. que anuncia e exige, a nova mulher não poderá surgir (...) Só poderia consegui-lo graças a uma evolução coletiva. Nenhum educador isolado pode fabricar hoje um 'ser humano fêmea' que não seja o homólogo exato do 'ser humano macho': educada como rapaz, a jovem sente-se excepcional e com isso sofre uma nova espécie de especificação. Stendhal bem o compreendeu quando dizia: 'É preciso plantar de uma só vez toda a floresta' (BEAUVOIR, 2016, pp. 550-551, vol. II).
\end{abstract}

Mas para isso é preciso que as mulheres se coloquem a caminho da libertação, e exijam, para além da igualdade formal e econômica, a igualdade moral, social e política. Sem esperar um movimento gratuito de generosidade por parte dos homens, é preciso continuar a caminhada e, na intersecção entre gênero, raça e classe, conseguir criar um nós que busque a libertação das mulheres, que, sem serem naturezas, são vistas como tais nas "atuais condições de educação e costumes".

\title{
Conclusão
}

Beauvoir se coloca, pois, contra a esquerda ortodoxa e mostra que a resolução da questão de classe não é suficiente para resolver a questão de gênero - a qual só poderá ser 
modificada por meio de uma luta conjunta das mulheres pelas mudanças das condições históricas atuais, que insistem em naturalizar o que é construção concreta. Se o trabalho é uma conquista a ser buscada, é preciso também estar alerta para suas armadilhas, pois, no caso das mulheres, ele traz consigo um aumento da carga horária de trabalho (a conjunção do trabalho fora e dentro de casa) e um aumento dos julgamentos morais sobre a mulher independente questões que também poderemos reencontrar em Angela Davis. Sem que possamos identificar seu pensamento ao da filósofa estadunidense, pudemos ao menos indicar aqui como algumas questões apontadas em $O$ segundo sexo ganharão peso na década de 80 , no livro Mulheres, raça e classe, o que mostra, para além da diferença radical da manutenção de Beauvoir ao pensamento eurocêntrico por colocar o mito da mulher sem perceber que ele se aplica apenas a um grupo de mulheres - algo que é muito criticado por Davis, - semelhanças no modo de pensar a intersecção das questões de gênero, raça e classe, e na necessidade de criar condições que possibilitem uma luta comum.

Para isso, a noção de situação é, em Beauvoir, fundamental. É por meio dela que podemos fugir de qualquer tentativa de naturalizar os e as existentes, e, ao mesmo tempo, admitir que essas existências, ao menos nas condições atuais, são divididas em gêneros. Assim, se a filósofa admite o peso da facticidade (o biológico, o psicológico e o econômico), é para afirmar que não se trata de uma natureza humana, e que, portanto, pode ser modificada por meio da transcendência, do ir além do dado. Resgatar a subjetividade (pensada agora em outra esfera que não a da racionalidade e completude) é essencial para pensar as possibilidades concretas de modificações das condições humanas, pois sem um papel constitutivo e ativo das subjetividades no mundo, não haveria como nem mesmo elaborar possibilidades de mudança. Mas a balança, nos textos de Beauvoir, não pende para o lado da subjetividade, dado que as afirmações sobre as atividades subjetivas vêm sempre junto com a impossibilidade de isolá-las de um certo contexto já dado e valorado. Não se trata, pois, de estabelecer uma subjetividade com poderes abstratos e uma liberdade absoluta, desconsiderando as condições concretas da espacialidade e temporalidade em que estão inseridas. Pelo contrário: trata-se de partir da facticidade, de compreender as atuais condições de ensino, de vivência na família, de como as crianças e adolescentes são criados, para verificar quais são as condições concretas de exercícios de libertação. A subjetividade nunca está totalmente separada da facticidade, que, por sua vez, nunca é totalmente separada de como as subjetividades a vivem e a significam.

Ou seja, é na tensão entre subjetividade - compreendida como transcendência - e facticidade - compreendida como imanência - que surge a situação das mulheres, em um 
equilíbrio instável entre dois elementos que não se identificam mas que, ao mesmo tempo, não se separam concretamente. E é ao utilizar a noção de situação dessa forma que Beauvoir consegue se manter simultaneamente contra o conceitualismo e o nominalismo, assumindo que ao menos provisoriamente "há mulheres", não porque ser mulher é uma Ideia inscrita em um Mundo Inteligível e Eterno, mas porque, ao olhar para a sociedade, podemos constatar que existem categorizações dadas. Ignorar essas categorizações, mantendo-se em afirmações verdadeiras, mas deveras abstratas como a de que "todos somos seres humanos", é, para a filósofa francesa, não uma forma de lutar contra as desigualdades de gênero, mas uma forma de ignorá-las. É preciso assumir como ponto de partida o que é dado pela sociedade em que vivemos, e a partir da constatação de que há mulheres, pensar uma luta comum contra as desigualdades, de forma a criar outra sociedade, na qual as possibilidades concretas de assumir suas subjetividades sejam mais igualitárias, e na qual, talvez, não faça mais sentido falar em gênero. 


\section{Notas}

${ }^{1}$ Professora Adjunta IV do Departamento de Filosofia e do Programa de Pós-Graduação em Filosofia. UFES Universidade Federal do Espírito Santo (UFES), Vitória, Brasil.

2 Subjetividade compreendida aqui como ser-no-mundo, como abertura (influência da fenomenologia heideggeriana). Falar em subjetividade é falar em seres humanos lançados na existência, no mundo e diante de outros seres humanos, tendo que inventar, com suas ações, os valores e sentidos da realidade. Subjetividade implica, portanto, intersubjetividade. Cf. BEAUVOIR. O existencialismo e a sabedoria das nações.

${ }^{3}$ Encontramos no livro diversas comparações entre a condição das mulheres, dos negros nos EUA e dos judeus. Sem identificá-las totalmente, Beauvoir faz uma análise comparativa entre alguns dos "excluídos da história" (para fazer referência ao título do livro de Michelle Perrot (1988)). Vale, ao menos como indicação, notar que, ao longo da escrita do livro O segundo sexo, Beauvoir fez inúmeras viagens aos EUA, pensando, por conta disso, questões raciais - algo que não é tratado de forma mais aprofundada no ensaio sobre gênero, mas que ao menos é indicado em vários momentos.

${ }^{4}$ Aqui Simone de Beauvoir segue a teoria psicanalítica, principalmente lacaniana, ao afirmar que o Olhar do outro é fundamental para nossa constituição e o modo como nos colocam no mundo. Cf. o capítulo "A infância" do segundo volume de $O$ segundo sexo.

${ }^{5} \mathrm{O}$ segundo desmame não corresponde ao desmame de fato, mas à negação da continuidade carnal com a mãe após o fim da amamentação. Cf. a parte Formação do Segundo Volume de O segundo sexo.

${ }^{6}$ Liberdade não significa conseguir tudo que se deseja, mas sim a própria possibilidade de desejar. Não é uma abstração, que não leva em conta as condições reais. Ser liberdade é o mesmo que ser transcendência, ou uma subjetividade que se encontra necessariamente no mundo, mas não tem o mesmo modo de existência que o mundo. Ver, para isso, a noção de moral existencialista tal como anunciada na Introdução do Primeiro Volume de $O$ segundo sexo e também no texto $O$ existencialismo e a sabedoria das nações.

${ }^{7}$ Ser-no-mundo e projeção são termos utilizados por Heidegger que Simone de Beauvoir traz para sua filosofia. Ela os transforma, no entanto, à revelia do filósofo alemão, em uma antropologia.

${ }^{8}$ Isso pode ser verificado na conclusão de $O$ segundo sexo, quando Marx é citado como aquele que melhor mostra a importância da independência feminina para a sociedade, e também na afirmação do projeto da revista Nouvelles Questions Féministes como sendo radical e materialista. Para isso, Cf. FALQUET, Jules. Nouvelles Questions Féministes In Estudos Feministas, set/dez/2004.

9 Porque se há determinismo total, não há nem mesmo possibilidade de mudança. Nesse sentido, podemos aproximar a noção de subjetividade trabalhada por Beauvoir com a de subjetividade ativa de María Lugones (Cf. LUGONES, 2014). Mesmo que esta critique o feminismo branco burguês europeu do qual Beauvoir participa (ao restringir o Mito da Mulher ao modo como esse grupo específico é visto), há também a ênfase nas formas de resistência infrapolíticas, possibilitadas por essa subjetividade ativa - que se aproxima muito da noção de Beauvoir da subjetividade como transcendência em tensão com a facticidade, tal como apontado neste artigo.

${ }^{10}$ Cf. principalmente capítulo 4 de DAVIS, A. Mulheres, raça e classe, quando a autora relata inúmeras ações de racismo por parte do movimento sufragista estadunidense.

${ }^{11}$ A entrevista pode ser vista em https://www.youtube.com/watch?v=xd4NzJ9XFrs. Acessado em 23/06/2017.

${ }^{12}$ Cf. Quarta Parte do Volume II, como veremos a seguir. 


\section{Referências bibliográficas}

BEAUVOIR, S. O segundo sexo. Rio de Janeiro: Nova Fronteira, 2016, vol. I.

. O segundo sexo. Rio de Janeiro: Nova Fronteira, 2016, vol. II.

. Le deuxième sexe I Paris: Gallimard, 2010.

. Le deuxième sexe II. Paris: Gallimard, 2010.

. O existencialismo e a sabedoria das nações. Lisboa: Esfera do Caos, 2008.

Por que sou feminista? Entrevista a Jean-Louis Servan-Schreiber. Disponível em:

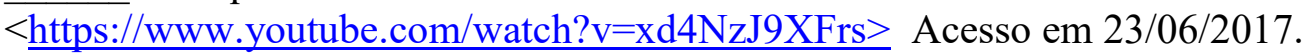

DAVIS, A. Mulheres, raça e classe. São Paulo: Boitempo, 2016.

DOS SANTOS, Magda G. Memória e feminino em Simone de Beauvoir: o problema da recepção. Estudos Feministas, set-dez/2012, pp. 919-937. Disponível em:

$<$ https://periodicos.ufsc.br/index.php/ref/article/view/S0104-026X2012000300018>. Acesso em 28/06/2017.

FALQUET, Jules. Nouvelles Questions Féministes: 22 años profundizando en una visión feministe, radical, materialista y anti-esencialista. Estudos Feministas, Florianópolis: setdez/2004, pp. 63-75. Disponível em:

$<$ https://periodicos.ufsc.br/index.php/ref/article/view/S0104-026X2004000300006 > Acesso em 23/06/2017.

KOFES, Suely. No labirinto, espadas e novelo de linha: Beauvoir e Haraway, alteridades, e alteridade, na teoria social. Revista Estudos Feministas, Florianópolis, set-dez/2008, pp. 865878. Disponível em: $<$ https://periodicos.ufsc.br/index.php/ref/article/view/S0104026X2008000300008> Acesso em 28/06/2017.

LECARME-TABONE, E. Le Deuxième Sexe de Simone de Beauvoir. Paris: Gallimard, 2008. 
LUGONES, María. Rumo a um feminismo descolonial In Estudos Feministas, Florianópolis, set/dez 2014, pp. 935-952. Disponível em

$<$ https://periodicos.ufsc.br/index.php/ref/article/view/36755> Acesso em 28/06/2017.

MISSAGIA, Juliana. Fenomenologia e feminismo: introdução e defesa de um diálogo profundo In PACHECO, J (org). Mulher \& Filosofia. Porto Alegre: Editora Fi, 2015.

PERROT, M. Os excluídos da história: operários, mulheres, prisioneiros. Rio de Janeiro: Paz e Terra, 1988.

RIBEIRO, D. Prefácio à edição brasileira In DAVIS, A. Mulheres, raça e classe. São Paulo: Boitempo, 2016. 